\title{
7 Day Comparative Effectiveness in Heartburn Relief and Endoscopic Healing. Randomized Controlled Trial using Omeprazole, Ranitidine, Antacids and Esolgafate, A Pre-Polymerized Cross-Linked Sucralfate (PCLS) Barrier Therapy
}

\author{
Ricky Wayne McCullough*1,2 \\ ${ }^{1}$ Translational Medicine Clinic and Research Center, USA \\ ${ }^{2}$ Department of Internal Medicine and Emergency Medicine, Warren Alpert Brown University School of Medicine, USA
}

*Corresponding author: Ricky Wayne McCullough, Translational Medicine Clinic

and Research Center, Storrs Connecticut, USA.

Received Date: February 24, 2020

Published Date: March 09, 2020

\begin{abstract}
Background: Barrier therapy has become an acceptable approach to manage heartburn in erosive gastro-esophageal reflux disease (eGERD). Following ingestion, pre-polymerized cross-linked formulation of standard sucralfate (PCLS, Esolgafate) self-anneals to achieve surface concentrations of sucralfate that is $2400 \%$ greater than otherwise possible using standard sucralfate.

Main argument: By blocking access of refluxate (bile acid, proteases, hydrochloric acid) to esophageal mucosa, PCLS is as effective as acid controlling therapies within the first 7 days of use.

Patients and methods: Multi-center randomized controlled trial in three university medical centers in Bangladesh used a protocol approved and registered with the Medical Research Council. Statistical power of this 4 arm trial required 9 participants per arm. Of 77 patients evaluated for severe dyspepsia, 42 had eGERD and were randomized into four treatment groups with 3 patients lost to follow up, thus leaving 39 for data analysis previously divided into 4 treatment arms that received either 1.5 gram bid sucralfate (PCLS), $20 \mathrm{mg}$ bid omeprazole, $150 \mathrm{mg}$ bid ranitidine or $30 \mathrm{ml}$ qid of aluminum/magnesium hydroxide antacid, $400 \mathrm{mg} / 400 \mathrm{mg}$ per $10 \mathrm{ml}$. Each group was assessed for (a) adverse events, (b) symptomatic relief, (c) endoscopic healing and (d) comparative association of relief as a function of healing.

Results: Comparable symptomatic relief occurred among 4 groups from $66 \%-90 \%$, but with divergent healing rates. There was $80 \%$ complete healing for PCLS compared to only $30 \%$ for omeprazole and $0 \%$ for ranitidine and antacids.

Conclusions: Relief by healing from PCLS in contrast to relief without healing from acid-controlling therapies implies acid exposure is not the single most significant contributor to eGERD symptoms, but that bile acids and proteases may also be involved. The latter observation is noteworthy when considering causes of nocturnal breakthrough heartburn and refractory GERD.
\end{abstract}

Keywords: Polymerized sucralfate; Barrier suspension; Erosive GERD

\section{Introduction}

Gastroesophageal reflux disease (GERD) is a condition that occurs when gastric contents reflux into the esophagus causing mucosal injury and troublesome symptoms commonly known as heartburn. It affects $25 \%$ to $40 \%$ of US and European population with $5 \%$ to $20 \%$ of the world population experiencing GERD in any given 3-month period [1]. Chronic symptomatic gastroesophageal 
reflux disease with erosive mucosal changes (eGERD) is a leading risk factor for esophageal adenocarcinoma (EAC) [2]. While only $10-15 \%$ of individuals with eGERD will have Barrett's esophagus (BE) [3], an estimated 95\% of newly diagnosed EAC have no prior history of Barrett's esophagus [4, 5]. This statistics implies existence of additional etiologic mechanisms causally related to the presence of GERD or eGERD. In addition to this, the demographic of GERD is shifting toward a younger patient cohort [6]. Therefore, it is desirable to have therapeutic options, in addition to existing ones, that combine symptomatic relief with cytoprotective reversal of mucosal injury. Breakthrough heartburn and refractory GERD remains a significant clinical concern with no clear therapeutic options.

By and large, recommended therapeutic approach to GERD or eGERD involves controlling acidity. A Cochrane meta-analysis of 134 trials involving nearly 36,000 patients with eGERD prescribed proton pump inhibitors (PPI), histamine 2 acid reducers (H2RA), sucralfate, antacids (AA) and others agents from 2 to 12 weeks [7] concluded that PPI therapy (omeprazole, pantoprazole), was the most effective therapy, H2RA therapy (ranitidine, cimetidine) was superior to placebo and that standard sucralfate 'had modest effect' for symptom relief and healing. Approximately 40\% eGERD patients refractory to PPI or other acid-control interventions $[7,8]$ therapeutic options that alter the course of disease turn on whether there is elevated esophageal acid exposure (EEAE) or not [9-11]. For patients with EEAE surgical intervention (fundoplication) is $80 \%$ successful [12] and is cytoprotective because it limits esophageal exposure to refluxate. For those who fail fundoplication and, even more, for non-EEAE individuals, there are few remaining options, to limit esophageal exposure to refluxate and thereby limit risk of Barret's Esophagus or EAC. It has been long established that refluxate of GERD and eGERD not only harbor acid but also contain proteases (e.g., pepsin) and conjugated bile acids [13-15]. In patients with refractory GERD, the percent of individuals exposed to reflux events is $37 \%$ if $\mathrm{pH}$ monitoring is used as a surrogate for reflux events [16]. However, when bile monitoring is combined with $\mathrm{pH}$ monitoring as an event measure of reflux, then the percent of individuals exposed to refluxate increases to $75 \%$ [16]. Thus, it is possible that patients with refractory GERD are symptomatically responding to bile reflux as well as acid reflux. In such cases, therapeutic options that exclusively target acid, even though associated with endoscopic healing, may still fail to protect against injury from reflux of bile acid into the esophagus and perhaps even worse, bile acid-related esophageal injury.

Bile salts formed in the liver by conjugating cholic acid and chenodeoxycholic acid with taurine and glycine form tauro- and glycol-conjugates, which become water soluble as the $\mathrm{pH}$ rises above 1. Some have suggested that acid suppression in patients with eGERD may increase incidence of Barrett's esophagus from duodenal reflux $[17,18]$, a post-prandial nocturnal reflux occurring when patients are recumbent or supine [13]. Data has emerged to suggest- ing bile acids, such as taurine conjugates, promote the development of eGERD and Barrett's esophagus [19, 20]. Possibly connected to a potential role for bile salts in development of eGERD, is data that suggesting eGERD to be a cytokine-driven inflammatory process [21] occurring in the esophageal mucosa and mediated by hypoxia inducible factor (HIF) 2a which, though generally transient, is stabilized and made to recur by repeated reflux of bile and acid. Esophageal perfusion studies in animal models have confirmed that taurine conjugates as toxic at $\mathrm{pH}$ below 7 causes esophageal mucosal damage [22,23], disrupts epithelial barrier by weakening tight junction proteins [24], dilates epithelial intercellular spaces [25] and leads to epithelial DNA damage while simultaneously inducing resistance to apoptosis [26]. The latter effect, inciting DNA damage while simultaneously preventing cell death (resisting apoptosis) may contribute to neoplastic changes in esophageal mucosal exposed to refluxate, thus plausibly giving rise to EAC. Notwithstanding these details, the 'broad picture' common theme of GERD is access of toxic refluxate to the esophageal epithelium resulting in deleterious consequences of repeated access of acidic and bilious refluxate - i.e., eGERD, Barrett's esophagus and EAC. Clearly, therapies targeting acid provide symptomatic relief and facilitate endoscopic healing. But they do not address clinically relevant injury from proteases and bilious backwash, injury that may be cytokine-driven and responsible for breakthrough heartburn and refractory GERD.

Therefore, this randomized trial assesses comparative efficacy of acid controlling therapies and a new sucralfate barrier therapy in terms of simultaneous symptomatic relief and mucosal protection. As a class, sucralfate, once polymerized by gastric acid, becomes agnostic to acid, bile or pepsin. It is a non-systemic site specific mucosal cytoprotectant having a physical mode of action that involves coating the mucosal lining. Theoretically, this mechanical coating limits access of refluxate to the esophageal epithelium. Despite being cytoprotective, non-systemic and having a physical mode of action, the more commonly known (first generation) standard sucralfate is ostensibly regulated as a 'drug'. This is because standard sucralfate, whether tablet, powder or a suspension, is biologically inert prior to ingestion. It relies on the body, specifically gastric acid, to convert it from its inert form into a biologically active form, a polymerized sucralfate, which then act as a barrier therapy, but one that is created by a chemical action (gastric acid polymerization) within the body following ingestion [27]. The sucralfate barrier therapy used in this trial is different. It is pre-polymerized and cross-linked during manufacture prior to patient use and does not require a chemical conversion by gastric acid to be biologically active. Pre-polymerized sucralfate is a biologically active barrier therapy first recognized by the US FDA in 2005 [28] as such and is currently regulated in the US as a medical device formulation of sucralfate. It is an ingestible polymerized sucralfate. Compared to the "drug" form of sucralfate, pre-polymerized sucralfate barrier therapy has significantly enhanced bioadherence. Three hours following 
administration, compared to standard sucralfate, pre-polymerized sucralfate achieves and maintains surface concentration of sucralfate that is $800 \%$ greater on normal mucosa and $2400 \%$ greater on injured or inflamed mucosal lining [29]. Therefore it has a greater barrier effect.

This randomized trial was undertaken to study the safety, quality of relief and endoscopic resolution of pre-polymerized sucralfate barrier therapy during in the first 7 days of treating erosive GERD. Comparative effectiveness of a barrier therapy to the standard of care was of interest, particularly for refractory GERD and nocturnal breakthrough heartburn. Therefore, active comparators were used - omeprazole, a proton pump inhibitor (PPI), ranitidine, a histamine 2-blocker acid reducer (H2RA) and common aluminum hydroxide and magnesium hydroxide antacid (AA). Of these three comparators, PPI have been identified by Cochrane meta-analysis as the preferred treatment for erosive GERD [7]. This comparison was previously reported in abstract form [30] but without a full narrative description of the trial. From a translational medicine perspective, it was of interest to explore the relationship between symptomatic improvement and endoscopic healing for all four interventions, because unlike acid-controlling therapies such as PPI, H2RA and AA, the clinical efficacy of sucralfate barrier therapy is indifferent to the presence acid, bile or proteases (e.g., pepsin). Clinical efficacy of a barrier therapy for eGERD is a measure of its ability to exclude access of refluxate to the esophageal mucosa.

\section{Methods}

\section{Objectives and hypotheses}

The main objective of this trial was to assess the seven day effectiveness and safety of polymerized sucralfate barrier therapy suspension in the treatment of erosive reflux disorder. In this trial their omeprazole, ranitidine and aluminum hydroxide/magnesium hydroxide antacid were used as comparators. In testing the efficacy of a new treatment, the use of comparators with known powered outcomes provides real world relevance and generalizability of results [31].

\section{Ethics and trial registration}

The trial was registered at Medical Research Council of Bangladesh (BMRC) [32] who provided institutional review of its protocol. Patients provided written informed consent to participate in the trial in accordance with the Declaration of Helsinki.

\section{Iso 14155 compliant clinical investigation of medical device}

For scientific transparency in the evaluation of medical devices [33], the current study was designed to be compliant with current ISO 14155 standards which addresses good clinical practice for the design, conduct, recording and reporting of clinical investigations carried out in human subjects [34]. The current trial assesses the safety and performance of Esolgafate as a barrier therapy medical device for NERD. Safety of sucralfate-based products is well doc- umented and has been established since 1968 [35]. Identified are rules and procedures of data collection, statistical power of the study and rationale of sample size. Recruitment of participants, randomization, concealment and allocation of interventions were performed in a manner to minimize bias, ensure collection of objective and credible data and support the overall goal of protecting patients' safety and well-being.

\section{Study design}

The study was 7 day multicenter randomized trial comparing efficacy between polymerized cross-linked sucralfate barrier therapy (PCLS, Esolgafate ${ }^{\mathrm{TM}}$ ) (1.5g sucralfate) twice daily, omeprazole $(20 \mathrm{mg})$ twice daily, ranitidine $(150 \mathrm{mg}$ ) twice daily or antacid (400mg aluminum hydroxide/400mg magnesium hydroxide per $10 \mathrm{ml}) 30 \mathrm{ml}$ taken four times daily. The study recruited 10 gastroenterologists as active investigators.

\section{Setting and participants}

Recruitment of participants took place in three medical center clinics where patients received primary and specialty medical care services.

\section{Inclusion criteria}

Inclusion criteria for male or females, with ages between 18 to 58 years (urban population), included dyspeptic symptoms (heartburn which included regurgitant reflux, postprandial chest discomfort) occurring 2-7 times per week for 3 months leading up to the study. There was a 7 day run in period following upper endoscopy. Included patients demonstrate ability to follow protocol instructions and complete self-administered questionnaire. All participants had the right to withdraw from the study at any time with no obligation to give reason for their decision.

\section{Exclusion criteria}

Excluded were individuals with Barrett's esophagus, peptic strictures, peptic ulcer disease or requiring motility altering drugs. Also excluded were individuals requiring medication for diabetes, hypertension or dyslipidemia. Individuals with alarm signs - difficulty swallowing, painful swallowing, gastrointestinal bleeding or anema, weight loss or history of cardiac chest pain, history of upper GI tract surgery, of cancer of head and neck and upper GI tract were excluded. Patients with known hypersensitivity to ingredients of the test treatments were excluded. Women who knew they were pregnant or were breastfeeding were excluded. Those with difficulty following protocol instructions (diary maintenance, keeping follow-up appointments etc) were excluded.

\section{Randomization criteria}

Participants were assigned by simple randomization into one of four groups, PSBT, omeprazole, ranitidine or antacid. Simple randomization was aided by use of a random number table wherein patients who had been assigned a two digit number from 01 to 70 plus were sequentially assigned to one of four treatment groups 
based on the first two digits of the random number table, crossing out random numbers that repeated or had been previously assigned to a patient.

\section{Interventions}

The intervention under investigation included omeprazole ranitidine, antacids and polymerized cross-linked sucralfate (PCLS) barrier therapy manufactured for Mueller Medical International (MMI) by Pharmaco Laboratories Pvt Ltd. The pharmacology of the former three interventions are well known, while that of PCLS is relatively new and differs significantly from in situ polymerized non-cross-linked sucralfate. The latter form of sucralfate is regulated as a drug due to required in situ polymerization by gastric acid following ingestion of biologically inert sucralfate. Polymerization ing 1.5grams of sucralfate) taken twice daily. and cross-linking process for PCLS involves use of cationic organic acid and is thereby more resistant to hydration than sucralfate polymerized by gastric acid. (Figure 1) below illustrates that 3 hours post-administration, PCLS achieves a maintains a surface concentration of sucralfate that is 7 fold (or $800 \%$ ) greater on normal or inflamed mucosa and 23 fold (or 2400\%) greater on acid-injured mucosa compared to gastric-acid polymerized sucralfate [29]. Omeprazole, ranitidine, antacid and PCLS were provided from existing stock of contract manufacturers inspected and certified for good manufacturing practices. Dosing of omeprazole was $20 \mathrm{mg}$ twice daily, of ranitidine $-150 \mathrm{mg}$ twice daily and or antacid was $30 \mathrm{ml}$ four times daily containing 400mg aluminum hydroxide/400mg magnesium hydroxide per $10 \mathrm{ml}$. Dosing volume PCLS was $15 \mathrm{ml}$ (contain-

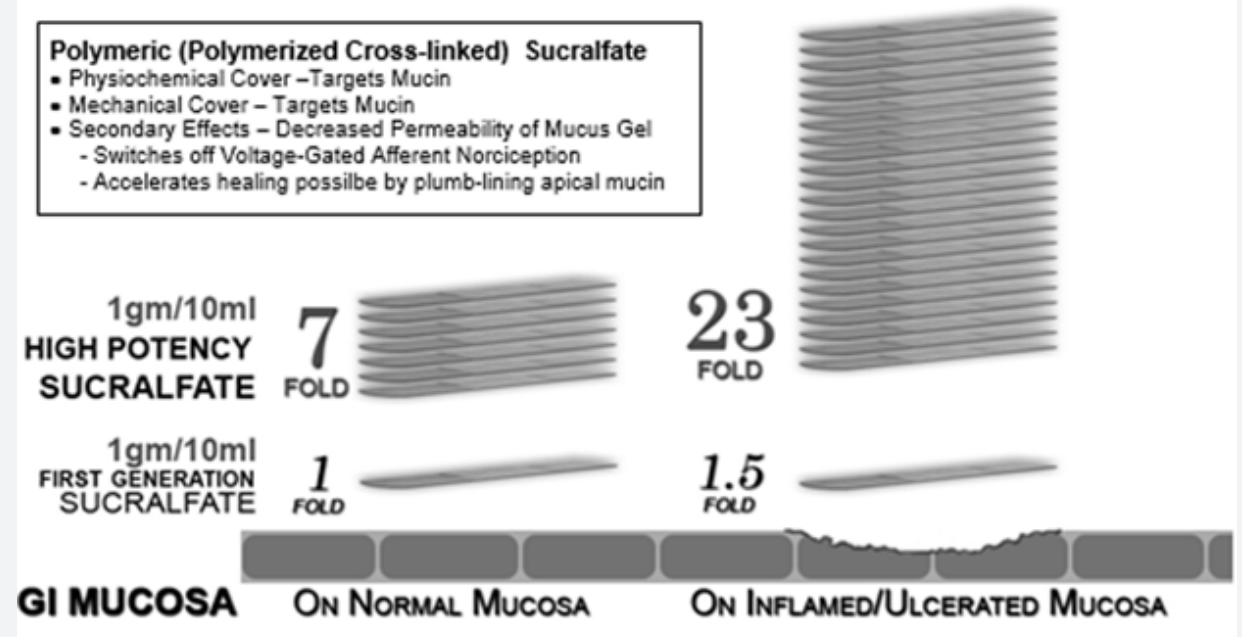

Figure 1: Exaggerated Muco-adherence Polymeric Sucralfate 3 hours Post-administration.

Study products were dispensed by a single hospital pharmacy assigned to all medical centers responsible for recruitment.

\section{Concomitant medications}

No additional medications were permitted during the period of 7 days.

\section{Allocation concealment and blinding}

Randomization numbers were assigned to participants and study products were packaged and assigned to patients based on their treatment arm. Any one participant was not aware of the three alternative treatments under investigation. Outcome assessors and person responsible for the statistical analysis were blinded to the intervention until completion of the study. Personal information about potential and enrolled participants was accessible only to the researchers involved in the trial.

\section{Compliance}

Participants were required to bring any remaining study product (including empty bottles) and diary to the study site at the end of the 7 day intervention period. Compliance with the study proto col was checked by tallying the amount of unused doses remaining in product bottles left. Generally, participants receiving less than $75 \%$ of recommended doses were considered noncompliant [36].

\section{Endpoints}

Primary outcome endpoints included overall relief of heartburn and overall healing. Secondary outcomes included comparative relief in terms of complete, partial and none, and comparative healing in terms of complete, partial and none between PCLS and acid-controlling therapies. The effect of an intervention's mode of action on efficacy outcomes was also examined.

\section{Quantization of symptom assessment}

Heartburn was defined as epigastric (subxiphoid) discomfort generally relieved by antacids or previously prescribed acid controller such as a PPI or H2RA. Heartburn at baseline and during trial was assessed daily using (a) Self-administered questionnaire for pain events and (b) 5-point Likert scale for pain intensity. Self-administered dairy recorded symptoms 4 times daily for 7 days (upon waking, midday, late afternoon/early evening, at bedtime) during 
the first week of non-intervention and any spurious attack. Patient graded symptom intensity using a 5 point Likert scale, where $0=$ absence of symptom, 1 = minimal awareness of symptom, easily tolerated, 2 = awareness of symptom, bothersome but tolerable without impairment of daily living or sleep, 3 = very bothersome interfering but not impairing daily living or sleep and $4=$ intolerable and impairing daily living or sleep. A daily total symptom score (dTSS) was obtained by adding the product of symptom occurrence multiplied by symptom intensity. Complete relief meant no episodes of heartburn from Day 3 onward. Partial relief meant 10-30\% decrease in heartburn intensity as measured by dTTS between Day 4 to Day 7. No relief meant continuance of heartburn without change in intensity as measured by dTTS from Day 4 to Day 7 .

\section{Healing assessment}

Endoscopies were preformed 7 days prior to start of intervention and on the 8th day following 7 days of intervention use. The Hetzel-Dent grading system [37] was used to assess GERD erosions. Complete healing occurred if there was endoscopic absence of erosions on Day 8, a Hetzel-Dent Grade 0 or 1. Partial healing was improvement by at least 1 Grade but still above Hetzel-Dent Grade 1. No healing was noted when there was complete absence of improvement in grade of erosions on Day 8.

\section{Comparative effectiveness assessments}

Comparative effectiveness outcomes were assessed using chisquare test of independence. Relationship between the quality of relief and healing was assessed between PCLS and each type of acid controlling therapy. Specifically, comparative distinction of complete and partial versus partial and no relief or healing was examined.

\section{Assessment of efficacy in mode of action}

For eGERD, healing is the ultimate goal of relief, and through this prism healing can be expressed in terms of relief by using a ratio between percent healing to percent relief, or an efficacy quotient. Notably omeprazole, ranitidine and antacids achieve healing by controlling acidity then complete reliance upon the length of time in acid-mitigation. Sucralfate-based therapies achieve healing by physical blockade of mucosal irritants - mineral acid, bile acids, proteases - and depend solely on their physical act of limiting mineral acid, bile acids and proteases access to the mucosa. Comparison of efficacy quotients provides another quantitative outcome measure and speaks to the quality of efficacy observed in the trial.

\section{Adverse events}

Adverse events (AEs) were collected Day 8 prior to endoscopy. An AE was defined as a negative medical event occurring during the 7 day study period, whether or not related to the study or interventions. Severe AE (SAE) were negative medical events that resulted in death, were life-threatening or, required emergency room care, hospitalization or resulted in severe (or persistent) disability or incapacitation.

\section{Power calculation}

The primary outcomes of the trial were esophageal healing and symptomatic relief (relief of heartburn and relief of reflux sensation). Based on Cochrane studies involving short term management of reflux disease [38], healing and symptomatic relief using a proton pump inhibitor (PPI) or histamine-2 blocker (H2B) occurred roughly $60 \%$ of the time compared to a placebo response of $15 \%$. Therefore, to detect a similar difference in this 7 day trial wherein the alpha error is 0.05 and beta error is 0.2 for a power of 0.8 , the sample size for the study should be 34 participants with 8.5 (or 9) patients in each of the 4 treatment arms. Assuming a 20\% loss to follow-up, 72 participants were recruited.

\section{Statistical analysis}

All analysis was conducted on an intention-to-treat basis, including all patients in groups to which they were randomized for whom outcomes would be available (including withdrawals and lost to follow-ups). Descriptive statistics were used to summarize baseline characteristics. The Student $t$ test was used to compare mean values of continuous variables for approximating a normal distribution. The chi-square test was used to compare percentages. Differences between study groups were considered significant when the $\mathrm{p}$ value was less than 0.05 , when $95 \%$ CI for RR did not include 1.0 or when the $95 \%$ CI for mean difference did not include 0 . All statistical tests were two tailed and performed at the $1 \%$ level of significance.

\section{Results}

\section{Conduct of the trial}

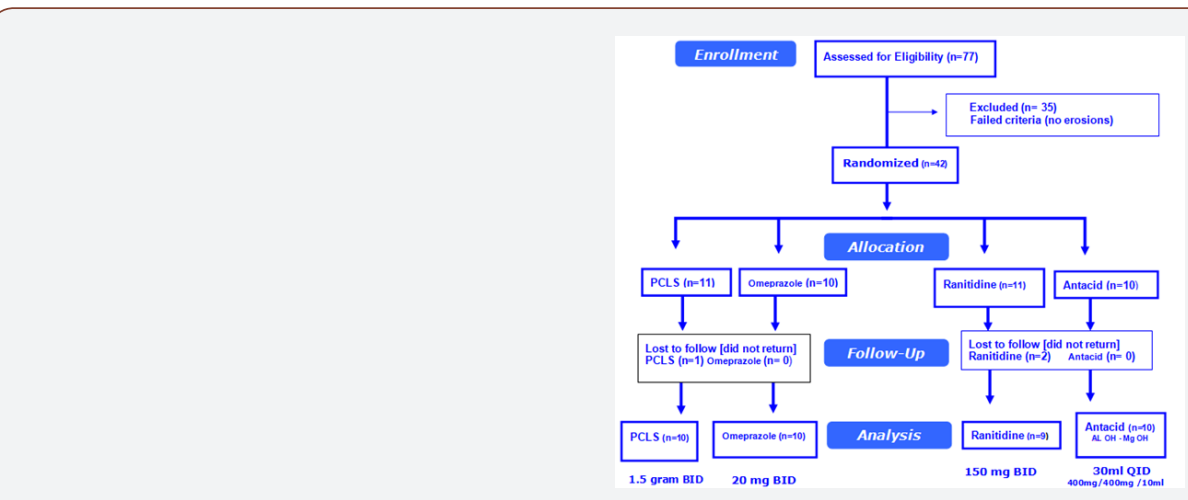

Figure 2: Patient Flow in 7 Day Erosive GERD Trial. 
A total of 77 patients with dyspepsia recruited by ten gastroenterologists were assessed for endoscopic eligibility for the trial resulting in 35 being excluded as having no erosions, that is, a Hetzel-Dent score of Grade 0 to 1 (Figure 2). The remaining 42 patients were randomized to 1 of 4 treatment arms.

\section{Adequacy of sample size}

The study was appropriately powered. Based on the statistical power applied to the study design, 8.5 participants per treatment arm were required. All treatment arms had at least 9 participants per intervention for a total of 42 participants for this 7 day trial (see Table 1, 'Patients Randomized').

\section{Participants}

Patients randomized into four treatment arms were comparable in age, gender, days per week of heartburn, severity of symptoms and of endoscopic erosions (Table 1). Patients had suffered from GERD for an average of $4.07 \pm 0.27$ years and most were treated with a PPI or PPI plus antacids. General age for participants in each treatment arm was similar.

Table 1: Baseline characteristics of Randomized Patients.

\begin{tabular}{|c|c|c|c|c|}
\hline Per Protocol Population & PCLS & Omeprazole & Ranitidine & Antacid \\
\hline Patients Randomized & 11 & 10 & 11 & 10 \\
\hline Patients Lost to Follow up & 1 & 0 & 2 & 0 \\
\hline Patients enter in Data & 10 & 10 & 9 & 10 \\
\hline Age, years Avg (Sd) & $37( \pm 12.2)$ & $39( \pm 10.1)$ & $41( \pm 11.5)$ & $43( \pm 9.1)$ \\
\hline Men & 7 & 7 & 6 & 6 \\
\hline Women & 4 & 3 & 5 & 4 \\
\hline Years with GERD & $4.5( \pm 2.3)$ & $3.8( \pm 2.1)$ & $3.9( \pm 1.9)$ & $4.1( \pm 1.8)$ \\
\hline \multicolumn{5}{|c|}{ No. Heartburn episodes per week [Likert Score] } \\
\hline 2: N (\%) & $2(18.2 \%)[\mathrm{L}=2]$ & $1(10 \%)[\mathrm{L}=1]$ & $3(27.3 \%)[\mathrm{L}=1]$ & $3(30 \%)[\mathrm{L}=2]$ \\
\hline 3: N (\%) & $1(9 \%)[\mathrm{L}=2]$ & $2(20 \%)[\mathrm{L}=2]$ & $2(18.2 \%) \mathrm{L}=2]$ & $2(20 \%)[\mathrm{L}=2]$ \\
\hline 4: N (\%) & $3(27.3 \%)[\mathrm{L}=3]$ & $4(40 \%)[\mathrm{L}=3]$ & $2(18.2 \%)[\mathrm{L}=3]$ & $3(30 \%)[\mathrm{L}=3]$ \\
\hline 6: N (\%) & $2(18.2 \%)[\mathrm{L}=3]$ & $2(20 \%)[\mathrm{L}=3]$ & $3(27.3 \%)[\mathrm{L}=2]$ & $1(10 \%)[\mathrm{L}=2]$ \\
\hline 7: N (\%) & $3(27.3 \%)[\mathrm{L}=2]$ & $1(10 \%)[\mathrm{L}=2]$ & $1(9 \%)[\mathrm{L}=2]$ & $1(10 \%)[\mathrm{L}=2]$ \\
\hline \multicolumn{5}{|c|}{ Hetzel-Dent Grade } \\
\hline Grade $0-1$ & 0 & 0 & 0 & 0 \\
\hline Grade 2 & 4 & 5 & 5 & 6 \\
\hline Grade 3 & 5 & 5 & 6 & 4 \\
\hline Grade 4 & 1 & 0 & 0 & 0 \\
\hline
\end{tabular}

\section{Compliance of the trial}

Compliance across all treatment arms was acceptable, though lower for PCLS (90.9\%) and ranitidine (81.8\%) due in large part to 3 patients lost to follow up, one from PCLS and two from ranitidine group, a male from the PCLS arm and a male and female from the ranitidine arm. Compliance in omeprazole (97.8\%) and antacids (99.3\%) arms were similar.

\section{Safety and adverse events}

All patients took multiple doses of each intervention and were included in the safety analysis. Results are presented for the intent to treat population. One patient taking PCLS (10\%), 2 patients taking omeprazole (20\%), 1 patient taking ranitidine $(11.1 \%)$ and 1 patient taking antacid arm (10\%) reported at least one AE. Adverse event of PCLS was oral hypesthesia (mild numbness of tongue), which was transient in nature lasting no more than a minute. One patient in the omeprazole group experience headache responsive to acetaminophen and one reported loose bowel movement which was intermittent. Both patients reporting an AE on ranitidine and the antacids reported nausea which was transient, lasting no more that one hour, resolving spontaneously without anti-emetics.

\section{Efficacy}

First primary outcome - symptomatic relief: (Table 2) shows 7day symptomatic relief of eGERD using PCLS, omeprazole, ranitidine and antacids and is presented in terms of complete, partial and no relief as previously defined.

Second primary outcome - healing: (Table 3) shows 7 day healing of eGERD using PCLS, omeprazole, ranitidine and antacids and is presented in terms of complete, partial and no healing as previously defined. The data of (Tables $2 \& 3$ ) are illustrated in (Figure 3). Notably, in 7 days substantial healing (80\% complete and $20 \%$ partial) occurred in the PCLS group, while minimal healing (30\% complete and 10\% partial) occurred in omeprazole group and inconsequential healing ( $0 \%$ complete, $11 \%$ partial for ranitidine, $10 \%$ partial for antacids) was observed in ranitidine and antacid treatment groups. 
Table 2: Symptomatic Relief following 7 Days Treatment With PCLS, Omeprazole, Ranitidine \& Antacids.

\begin{tabular}{|c|c|c|c|c|c|}
\hline Interventions & Patients & Complete Relief & Partial Relief & No Relief & Overall Relief \\
\hline PCLS & 10 & $50 \%(\mathrm{n}=5 / 10)$ & $30 \%(\mathrm{n}=3 / 10)$ & $20 \%(\mathrm{n}=2 / 10)$ & $80 \%(\mathrm{n}=8 / 10)$ \\
\hline PPI & 10 & $40 \%(\mathrm{n}=4 / 10)$ & $50 \%(\mathrm{n}=5 / 10)$ & $10 \%(\mathrm{n}=1 / 10)$ & $90 \%(\mathrm{n}=9 / 10)$ \\
\hline H2B & 9 & $44 \%(\mathrm{n}=4 / 9)$ & $22 \%(\mathrm{n}=2 / 9)$ & $33 \%(\mathrm{n}=3 / 9)$ & $67 \%(\mathrm{n}=6 / 9)$ \\
\hline AA & 10 & $30 \%(\mathrm{n}=3 / 10)$ & $50 \%(\mathrm{n}=5 / 10)$ & $20 \%(\mathrm{n}=2 / 10)$ & $80 \%(\mathrm{n}=8 / 10)$ \\
\hline
\end{tabular}

PCLS- Polymerized Cross-Linked Sucralfate Barrier Therapy; PPI -Proton Pump Inhibitor (omeprazole); H2B -Histamine Blocker (ranitidine); AAAntacids

Table 3: Healing following 7 Days Treatment With PCLS, Omeprazole, Ranitidine \& Antacids.

\begin{tabular}{|c|c|c|c|c|c|}
\hline Interventions & Patients & Complete Healing & Partial Healing & No Healing & Overall Healing \\
\hline PCLS & 10 & $80 \%(\mathrm{n}=8 / 10)$ & $20 \%(\mathrm{n}=2 / 10)$ & $0 \%(\mathrm{n}=0 / 10)$ & $100 \%(\mathrm{n}=10 / 10)$ \\
\hline PPI & 10 & $30 \%(\mathrm{n}=3 / 10)$ & $10 \%(\mathrm{n}=1 / 10)$ & $60 \%(\mathrm{n}=6 / 10)$ & $40 \%(\mathrm{n}=4 / 10)$ \\
\hline H2B & 9 & $0 \%(\mathrm{n}=0 / 9)$ & $11 \%(\mathrm{n}=1 / 9)$ & $88.9 \%(\mathrm{n}=8 / 9)$ & $11 \%(\mathrm{n}=1 / 9)$ \\
\hline AA & 10 & $0 \%(\mathrm{n}=0 / 10)$ & $10 \%(\mathrm{n}=1 / 10)$ & $90 \%(\mathrm{n}=9 / 10)$ & $10 \%(\mathrm{n}=1 / 10)$ \\
\hline
\end{tabular}

PCLS- Polymerized Cross-Linked Sucralfate Barrier Therapy; PPI- Proton Pump Inhibitor (omeprazole); H2B- Histamine Blocker (ranitidine); AAAntacids

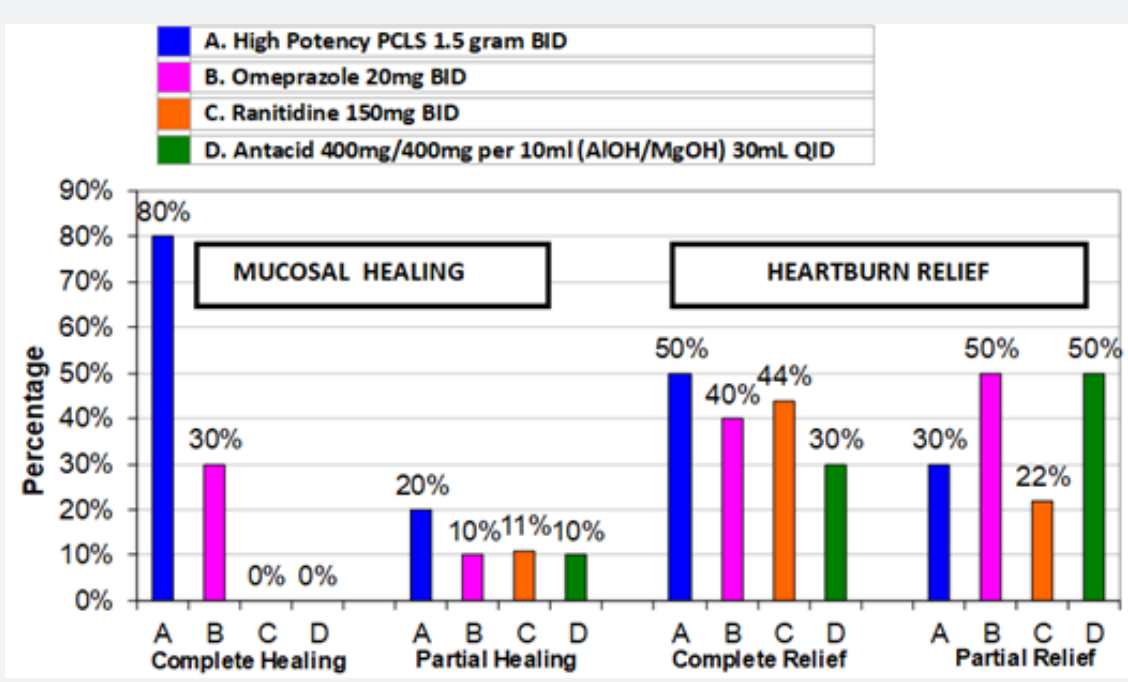

Figure 3: Healing and Symptomatic Relief of eGERD.

From (Figure 3), qualitatively, it would appear that all interventions were comparable in terms of complete and partial relief. However, when data is rendered in terms of comparing complete/ partial relief to complete/partial healing (Figure 4) visual distinctions emerge. At a glance the 7 day comparative relief (complete plus partial) among the four treatment groups appears largely

Table 4: Chi Square Value 7 Day Comparative Effectiveness for Overall Healing.

\begin{tabular}{|c|c|c|c|c|}
\hline Comparative Interventions & Complete Healing & Partial Healing & No Healing & $\chi \mathbf{2}$ \\
\hline PCLS & $80 \%(\mathrm{n}=8 / 10)$ & $20 \%(\mathrm{n}=2 / 10)$ & $0 \%(\mathrm{n}=0 / 10)$ & 83.12 \\
\hline Omeprazole & $30 \%(\mathrm{n}=3 / 10)$ & $10 \%(\mathrm{n}=1 / 10)$ & $60 \%(\mathrm{n}=6 / 10)$ & $\mathrm{p}<0.00001$ \\
\hline PCLS & $80 \%(\mathrm{n}=8 / 10)$ & $20 \%(\mathrm{n}=2 / 10)$ & $0 \%(\mathrm{n}=0 / 10)$ & 165.7 \\
\hline Ranitidine & $0 \%(\mathrm{n}=0 / 9)$ & $11.1 \%(\mathrm{n}=1 / 9)$ & $88.9 \%(\mathrm{n}=8 / 9)$ & $\mathrm{p}<0.00001$ \\
\hline PCLS & $80 \%(\mathrm{n}=8 / 10)$ & $20 \%(\mathrm{n}=2 / 10)$ & $0 \%(\mathrm{n}=0 / 10)$ & 167.4 \\
\hline Antacid & $0 \%(\mathrm{n}=10 / 10)$ & $10 \%(\mathrm{n}=1 / 10)$ & $90 \%(\mathrm{n}=9 / 10)$ & $\mathrm{p}<0.00001$ \\
\hline
\end{tabular}

Chi Square Value 7 Day Comparative Effectiveness for Overall Healing. 


\section{Comparative effectiveness assessments}

One aspect of meaningful effectiveness relates to the combined degree of complete and partial relief, and combined degree of complete and partial healing. Table 4 shows effectiveness of PCLS in healing when compared to the three other treatment groups. In comparing PCLS with acid-controlling therapies for 7 day healing, chi-square statistics were large with $p$ values less than 0.00001 at significance of $\mathrm{p}<0.01$.

Table 5: Chi Square Value 7 Day Comparative Effectiveness for Overall Relief.

\begin{tabular}{|c|c|c|c|c|}
\hline Comparative Interventions & Complete Relief & Partial Relief & No Relief & $\chi \mathbf{2}$ \\
\hline PCLS & $50 \%(\mathrm{n}=4 / 10)$ & $30 \%(\mathrm{n}=3 / 10)$ & $20 \%(\mathrm{n}=2 / 10)$ & $\mathrm{p}=0.44$ \\
\hline Omeprazole & $40 \%(\mathrm{n}=3 / 10)$ & $50 \%(\mathrm{n}=7 / 10)$ & $10 \%(\mathrm{n}=1 / 10)$ & 4.44 \\
\hline PCLS & $50 \%(\mathrm{n}=4 / 10)$ & $30 \%(\mathrm{n}=3 / 10)$ & $20 \%(\mathrm{n}=2 / 10)$ & $\mathrm{p}=0.1078$ \\
\hline Ranitidine & $44.5 \%(\mathrm{n}=4 / 9)$ & $22.2 \%(\mathrm{n}=2 / 9)$ & $33.3 \%(\mathrm{n}=3 / 9)$ & 10 \\
\hline PCLS & $50 \%(\mathrm{n}=4 / 10)$ & $30 \%(\mathrm{n}=3 / 10)$ & $20 \%(\mathrm{n}=2 / 10)$ & $\mathrm{p}=0.0067$ \\
\hline Antacid & $30 \%(\mathrm{n}=3 / 10)$ & $50 \%(\mathrm{n}=5 / 10)$ & $20 \%(\mathrm{n}=2 / 10)$ & \\
\hline
\end{tabular}

PCLS- Polymerized Sucralfate Barrier Therapy; PPI- Proton Pump Inhibitor (omeprazole); H2B- Histamine Blocker (ranitidine); AA- Antacids

Table 5 shows effectiveness of PCLS in providing relief when compared to the three other treatment groups. While each intervention provided relief well above $60 \%$ (Table 2, Figures $3 \& 4$ ), more participants experienced partial relief with omeprazole and antacids than with PCLS. The difference between PCLS and ranitidine in terms of overall relief in 7 days , though trending toward sig- nificance, was in fact statistically insignificant. In comparing PCLS with acid-controlling therapies for 7 day relief, the chi-square statistics were small, significant only when compared to omeprazole and antacids and appeared to favor the acid controlling therapies. However relief from acid-controlling therapies was poorly associated with mucosal healing.

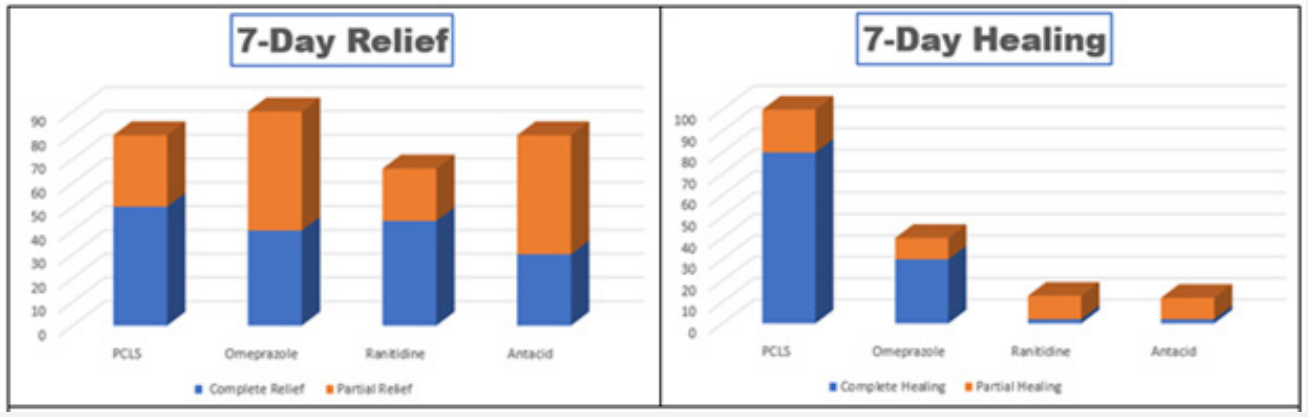

7-day extent of relief of erosive GERD compared to 7-day extent of healing in each treatment arm: Only in the PCLS treatment group was the extent of relief commensurate with extent of healing.

PCLS- Polymerized Cross-Linked Sucralfate Barrier Therapy; PPI- Proton Pump Inhibitor (omeprazole); H2B- Histamine blocker (ranitidine); AA- Antacids.

Figure 4: Relationship between Complete and Partial Relief \& Healing of eGERD.

\section{Assessment of efficacy in mode of action}

For eGERD, healing is the ultimate goal of relief, and through this prism, healing can be expressed in terms of relief by using a ratio between percent healing to percent relief. This healing/relief quotient assesses the quality of efficacy and is reflective of the value of an intervention's mode of action. Figure 5 compares efficacy quotients, that is, the extent of healing as it relates to relief for the four treatment arms. Using differing mechanisms of actions, omeprazole, ranitidine and antacids target $\mathrm{pH}$ to reduce or eliminate acidity. Reducing acidity over first 7 days while providing substan- tial relief, is in fact associated with limited healing. Contradistinctively, limiting physical access of refluxate to the mucosa (as does PCLS) is associated with healing rates that are 2-10 fold better than that observed for acid controlling therapies over the same period of time. While comparative relief is largely similar and quantitatively high for all four interventions (Figure 4), Figure 5 shows that overall healing plays a much smaller role in the symptomatic relief experienced with acid controlling interventions. However, the converse is true for the PCLS treatment group where overall relief is substantially (and likely causally) related, to healing regardless of the $\mathrm{pH}$ of the refluxate. 


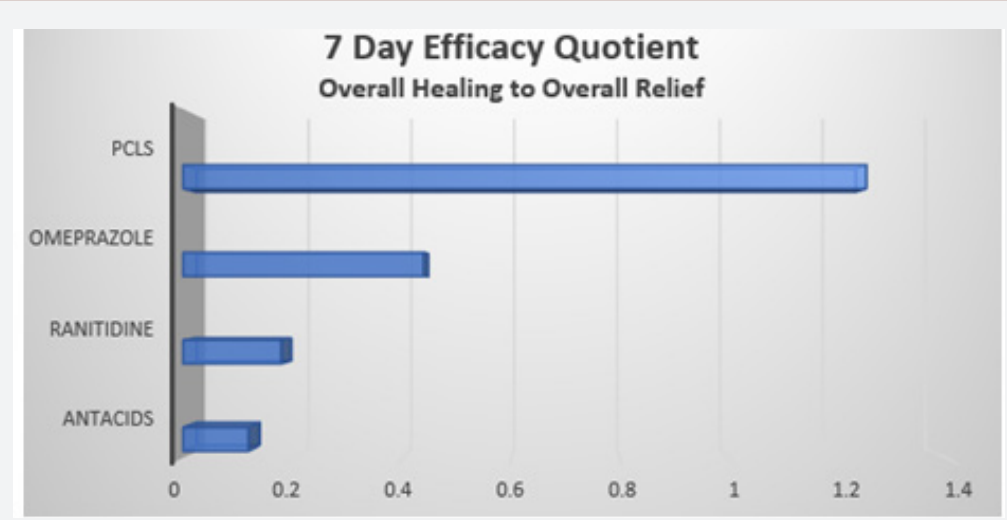

7-day efficacy quotient is the ratio of relief as a function of healing. Only in PCLS treatment group did healing reflect relief. This imply that factors associated with healing are causally associated with factors associated with relief. This possible causal link was not apparent with acidcontrolling therapies. That is, for the first 7 days of use, factors associated with relief from acid controlling therapies, were not in lockstep with factors associated with healing.

Figure 5: Relationship Between Overall Healing and Overall Relief.

\section{Discussion}

This study on the symptomatic and endoscopic relief of erosive GERD was a seven day randomized active control comparative effectiveness trial. It examined the comparative efficacy between three examples of acid controlling therapies, representing the standard of care and a medical device, pre-polymerized sucralfate barrier therapy. The trial was an ISO 14155 compliant clinical investigation of a medical device reviewing the safety and efficacy of polymerized sucralfate barrier therapy in a manner that was statistically relevant. The trial was properly power with appropriate sample sizes per treatment arm, conducted transparently and had no significant compliance issues among participants whose clinical characteristics were evenly distributed among treatment arms. Therefore, relevant conclusions could be made on outcomes. Efficacy was assessed by quantifying symptomatic relief, endoscopic healing and the ratio of each as a measure of overall efficacy.

As expected omeprazole, ranitidine and antacids provided significant symptomatic relief of eGERD within the first 7 days. Unanticipated was that polymerized sucralfate barrier therapy would provide similar significant symptomatic relief. The expected experience of standard sucralfate for symptomatic relief of eGERD is that 7 days would be insufficient time to provide symptomatic relief on par with standard of care therapeutic options. Specifically, Vermeijden et al [39] reported the best known outcomes for sucralfate in the treatment of eGERD. Using standard sucralfate, patients required 56 days to achieve $80 \%$ symptomatic relief. In this trial, pre-polymerized sucralfate required only 7 days for $80 \%$ symptomatic relief. Additionally, Vermeijden et al. [39] observed that in 56 days, 4 grams daily of standard sucralfate (or 224 grams) was required to achieve a healing rate of $68 \%$. In this trial using 3 grams per day for 7 days (or 21 grams) of pre-polymerized sucralfate suspension barrier, $80 \%$ complete healing and $20 \%$ partial healing was achieved.
In this comparison, clearly the biophysical distinction of pre-polymerized sucralfate in achieving and maintaining surface concentrations of sucralfate that is $800 \%$ to $2400 \%$ greater than standard sucralfate (Figure 1) has significant clinical relevance. As to potency, 21 grams of sucralfate in PCLS used over 7 days achieved symptomatic relief and healing rates comparable to 224 grams of standard sucralfate used over 56 days, as observed by Vermeijden, et al. [39]. The implication is stark. Using pre-polymerized sucralfate suspension barrier in patients suffering from eGERD may require $1 / 10$ the dose of standard sucralfate over $1 / 12$ the time to achieve comparable relief and healing. This was accomplished in 7 days versus 56 days which represents a $78 \%$ reduction in time.

Pre-polymerized sucralfate suspension barrier was found to be safe and more importantly no less safe than omeprazole, ranitidine or antacids. Commonly known self-limited adverse events for omeprazole [40], ranitidine [41], antacids [42] and sucralfate therapies [43] were observed in this trial. As regards aluminum exposure posed by antacids and sucralfate, it has been well established that 4 grams of standard sucralfate provides no greater exposure than the prescribed use of aluminum containing antacids when taken over equivalent periods of time [44, 45]. Additionally, oral aluminum bioavailability is greater from water than from aluminum hydroxide antacids or from standard dose sucralfate [46]. Specifically, oral aluminum bioavailability from drinking water is 0.22 to $0.35 \%[47,48]$ compared to $0.001 \%$ to $0.007 \%$ from sucralfate or aluminum-containing antacids $[45,49,50]$. Just as antacids containing aluminum salts, so too sucralfate is safe to be used in pregnant women as well as for women during labor for aspiration prophylaxis [50]. Though little is known regarding use of aluminum-containing antacids and sucralfate in breast-feeding females, aluminum is known to be endogenous in breast milk [51,52]. Indeed, however, for patient subpopulations with impaired renal function, any aluminum-containing product should be minimally used if at all [53]. For patients with normal renal function, a meta-analysis review by the 
European Commission Scientific Committee on Health \& Consumer Safety could not identify causal correlation between neurological conditions and ingestion of aluminum-containing products [46].

Turning to efficacy, to be an acceptable alternative to existing treatment options for erosive GERD (omeprazole, ranitidine and antacids), the suspension form of polymerized sucralfate barrier therapy, needed to have demonstrated that statistically it is no less effective. Rapidity of relief as a measure of efficacy was one focus of this 7 day trial. The 7 day overall symptomatic relief (complete plus partial) for PCLS, omeprazole, ranitidine and antacids was $80 \%$, $90 \%, 67 \%$ and $80 \%$ respectively (Table 2 ). Clearly PCLS is not less effective than either acid-controlling therapy, as rapidity of relief was roughly equivalent for all interventions. Additionally, it can be said that in terms of patients experiencing no relief within 7 days, pre-polymerized sucralfate barrier suspension was no less effective than omeprazole, ranitidine and antacids where respective outcomes were $20 \%, 10 \%, 33 \%$ and $20 \%$. Of note, as to complete (vs overall) relief, using 1.5 grams of polymerized sucralfate suspension twice daily was substantially equivalent to complete relief observed with omeprazole $40 \mathrm{mg}$ daily dose and better than that observed with ranitidine or antacids. The author is unaware of were sucralfate-based therapy demonstrating such an outcome within 7 days. In terms of overall healing (complete and partial) and in terms of healing as a function of relief, pre-polymerized sucralfate barrier suspension was statistically superior to omeprazole, ranitidine or antacids. After 7 days, complete endoscopic remission of erosive GERD was $80 \%$ using pre-polymerized sucralfate barrier suspension compared to $30 \%$ for omeprazole and $0 \%$ for both ranitidine and antacids. All patients using pre-polymerized sucralfate barrier suspension evidenced some extent of healing either complete $(80 \%)$ or partial $(20 \%)$; there were no PCLS patients who failed to exhibit healing. This was in contrast to participants using omeprazole, ranitidine and antacids, wherein no healing was observed over 7 days in $60 \%, 88 \%$ and $90 \%$ of patients respectively.

Healing as a function of relief was an outcome purposely selected to examine efficacy of mechanism (Figure 5). Acid controlling therapies provide relief with endoscopic healing as a consequence of elevating pH. Pre-polymerized sucralfate provide symptomatic relief as a consequence of cytoprotective exclusion of acid, bile and proteases [27]. This mechanism of cytoprotective exclusion was associated with 7 day accelerated healing and may speak to the need to prevent access of refluxate to the esophageal epithelium. Rapid 7 day symptomatic relief linked to simultaneous endoscopic healing of esophageal erosions has not been reported for any anti-GERD therapy. Particularly it has not been reported for any sucralfate-based therapy. Most trials involving endoscopic reversal of erosions involve acid-controlling therapies and require 6 to 8 weeks, with a few that have been as short as 4 weeks [7], but certainly none within 7 days.

Beside this finding, a key observation in this trial was that re- lief by healing from PCLS, in contrast to relief without healing from acid-controlling therapies, implies that acid exposure may not be the single most significant contributor to eGERD symptoms. PCLS is $\mathrm{pH}$-agonistic and exerts a physical action to deny components of gastric refluxate any significant access to the esophageal mucosa. It is undeniable that gastric refluxate creates mucosal reactions that lead to visual erosions of eGERD. Current therapy guidelines for eGERD [54] promote acid-controlling therapies as the centerpiece of management and specifically exclude standard sucralfate as having any role. Of course, the data reported here not only suggest that PCLS form of sucralfate may have a role in the management of eGERD, but that its role as barrier therapy may be physiologically important beyond the exclusion of acid. Clearly if acidic hydrogen protons were the sole irritant within gastric refluxate causing mucosal erosions, then at least, omeprazole and ranitidine should have shown complete healing rates beyond $30 \%$ and $0 \%$ respectively. They did not. Only with PCLS treatment which is $\mathrm{pH}$-agonistic, did the extent of healing reflect the extent of relief. This implies that factors associated with healing are causally associated with factors associated with relief, and that there are factors within gastric refluxate other than acidic hydrogen protons, responsible for mucosal inflammatory reaction to reflux. A possible causal link of irritants causing mucosal inflammation other than hydrogen protons is not apparent from the relief and delayed healing using acid-controlling therapies. That is, for the first 7 days of use, factors associated with relief from acid controlling therapies, were not lock-stepped with factors associated with healing. In other words, for the first 7 days of therapy, the onset of relief by acid elimination is not a bellwether for histologic improvement of eGERD syndrome. There are additional components of refluxate that the mucosa is reacting to, components responsible for continued mucosal inflammation.

An alternative view is that within the first 7 days, the constituent components of refluxate that give rise to pain, have a discontinuous interactive relationship with tissue components responsible for healing or for reduced inflammation. In other words, refluxate exposure is not purely acid exposure. Besides caustic acid, serine proteases and dissolved conjugated bile acids backwash on to the esophageal epithelium. Acid is detected by ASIC and TRPV1 nociceptors $[55,56]$ on afferent neurons buried within the submucosa. Within the eGERD phenotype, acid excitation of these receptors is a signficant factor of symptomatic reflux. However, both bile [15,19,24-26] and serine proteases [57] within gastric refluxate [13] trigger increased submucosal expression of TRPV1 and proteinase-activated receptor-2 (PAR2), and the latter (PAR2) induces proinflammatory and neuroinflammatory effects [58-60] that slow healing. Acid sensation symptomatically controlled by PPI, H2RA, AA occurs without significant healing. However, acid sensation symptomatically controlled by PCLS (which has no affect on acidity of gastric refluxate), occurs in concert with healing at a relatively rapid pace, that is, within 7 days. Besides the implication that other non-acid irritants are similarly responsible for mucosal inflam- 
mation, the sheer rapidity of healing implies that with pro-inflammatory processes, there were counterbalancing processes within the esophageal mucosa, that is, anti-inflammatory processes were readily (and perhaps reflexively) available in the mucosa to facilitate $80 \%$ complete healing and $20 \%$ partial healing within 7 days of using PCLS. This principle or law of feedback-ready homeostatic processes has been discussed elsewhere regarding patients with irritable bowel syndrome who used PCLS [61].

In using acid-controlling treatments for the first 7 days, healing is slowed by persistent access to mucosa of non-acid irritants, irritants that induce inflammation resistant to immediate healing. Physical denial of acid irritants and non-acid irritants permit rapid resolution of inflammation that is not possible using acid controllers within the first 7 days. That omeprazole was associated with minimal, but definite complete healing (30\%), may not be entirely attributable to acid-blockade. Direct, non-acid related anti-inflammatory effects of omeprazole have been reported [62, 63], which may explain the observation of a small degree of healing with omeprazole in this trial yet none with ranitidine and antacids. What seems clear, however, is that strict physical barrier exclusion of reflaxate irritants appear to have resulted in an immediate onset of healing in the PCLS treatment group. In the first 7 days, broad barrier exclusion of irritants appears to be a stronger contributor to healing than pure acid neutralization, acid reduction/blockade or any nascent anti-inflammatory action of omeprazole.

\section{Conclusion}

Seven day symptomatic relief of erosive GERD addresses an unmet medical need. Current guidelines for the management of eGERD [54] center on acid mitigation, using antacids, acid reducers (H2RA) and acid blockers, PPI [62]. Barrier therapies such as alginate [64] and hyaluronate chondroitin polymer complex [65] have been used. Still patients continue to suffer from erosive GERD [67, 68]. The patient cohort is trending younger [6] and the incidence of adenocarcinoma of esophagus is trending upward [69]. To curve the clinical trajectory of eGERD and its epidemiology, persistent access of gastroduodenal refluxate to the esophageal mucosa has should be effectively prevented. Acid controlling therapies provide symptomatic relief, are associated with endoscopic remission of eGERD following weeks of treatment but cannot deny bile or serine proteases access to vulnerable esophageal mucosa. While fundoplication is an effective anti-reflux treatment, a non-invasive approach such as a mucin-binding sucralfate barrier should be more preferred. Pre-polymerized sucralfate barrier suspension is a non-systemic cytoprotective physical mode of treating eGERD. In this 7 day trial pre-polymerized sucralfate was found to be as effective as acid-controlling therapies for symptomatic relief. The nature of PCLS-mediated relief involved substantial elimination of inflammation as symptomatic relief was simultaneously associated with 80\% complete and 20\% partial healing. With PCLS, the hallmark of physical blockade of non-acid and acid irritants is substantial early healing which was not observed with omeprazole, ranitidine and antacids. Unlike pre-polymerized sucralfate, standard sucralfate therapies are less effective than the existing and more preferred acid controlling therapies tested in this trial. For standard sucralfate, 224 grams is required over 56 days to achieve $68 \%$ healing rate [39], which is less potent than pre-polymerized sucralfate barrier suspension which required 21 grams over 7 days to achieve $80 \%$ complete healing and $20 \%$ partial healing.

There were several significant findings in this trial. First, acid controllers relieving by targeting $\mathrm{pH}$ or acidic hydrogen proton have no immediate impact on healing mucosal erosions. That is, the mucosa of eGERD continues to be inflamed despite significant symptomatic acid relief. Second, symptomatic relief from PCLS is associated with substantial healing within 7 days, implying that physical blockade of gastric refluxate involve exclusion of proton acid as well as non-proton acid irritants. Third, acid relief may not be an adequate barometer of how well eGERD treatment is progressing. This is particularly true since $90 \%$ of newly diagnosed adenocarcinoma appear related to GERD and not to Barrett's esophagus $[2,4,5,70]$; and acid controlling therapies do not reduce mucosal exposure to bile or serine proteases. Fourth, persistent exposure to non-acid irritants such as bile salts and serine proteases have been linked to cytokine inflammatory processes that give rise to metaplasia and may emerge as a more important target in the management of eGERD. This makes effective barrier therapy as important if not more important than acid control. Pre-polymerized sucralfate barrier therapy is not a drug but a medical device, a barrier therapy containing the active clinical form of sucralfate. In this trial PCLS provided symptomatic relief as a function of mucosal healing while acid-controlling therapies provided equivalent symptomatic relief that was independent of healing. Pre-polymerized sucralfate was found to be safe, statistically effective and may provide a meaningful non-chemical biophysical mode of management for eGERD.

\section{Acknowledgement}

Contracted trial director: Professor AK Azad Khan delegated responsibilities.

Contracted lead coordinator: Dr. Mian Mashed Ahmad lead coordinator responsible for organizing patient recruitment, management of endoscopies and scoring patient outcomes.

Contracted contributing investigators: Dr. MA Masud, Dr. Swapan Chandra Dhar, Dr. Md. Habibur Rahman, Dr. Dewan Saifuddin Ahmad, Dr. Hafeza Aftab, Dr. Hasan Masud, Dr. Naima Haque, Dr. Anisur Rahman, Dr. Mahmud Hasan. Each were responsible for patient assessment and test drug distribution.

Medical institutions: Department of Gastrointestinal \& Liver Diseases, Dhaka Medical College Hospital (DMCH), Dhaka, Bangladesh; Department of Gastroenterology, Bangabandhu Sheikh Mujib Medical University (BSMMU), Dhaka, Bangladesh; Department of Gastrointestinal, Hepatobiliary and Pancreatic Disorders (GHPD) and Research Division, Bangladesh Institute of Research \& Rehabil- 
itation in Diabetes, Endocrine and Metabolic Disorders (BIRDEM), Dhaka, Bangladesh.

Trial Concept, Methodology, Data curation, literature research, formal analysis, writing, editing manuscript: RW McCullough MD.

\section{Conflict of Interest}

No conflict of interest.

\section{References}

1. Toghanian S, Wahlqvist P, Johnson DA, Bolge SC, Liljas B (2010) The burden of disruption gastro-oesophageal reflux disease: a database study in US and European cohorts. Clini Drug Investig 30(3): 167-178.

2. Rubenstein JH, Taylor JB (2010) Meta-analysis: the association of oesophageal adenocarcinoma with symptoms of gastro-oesophageal reflux. Aliment Pharmacol Ther 32(10): 1222-1227.

3. Johansson J, Håkansson HO, Mellblom L, Kempas A, Johansson KE, et al. (2005) Prevalence of precancerous and other metaplasia in the dista oesophagus and gastro-oesophageal junction. Scand J Gastroenterol 40(8): 893-902.

4. Sikkema M, de Jonge PJ, Steyerberg EW, Kuipers EJ (2010) Risk of esophageal adenocarcinoma and mortality in patients with Barret's esophagus: a systematic review and meta-analysis. Clin Gastroenterol Heptol 8: $234-244$

5. Corley DA, Levin TR, Habel LA, Weiss NS, Buffler PA (2002) Surveillance and survival in Barrett's adenocarcinomas: a population-based study. Gastroenterol 122: 633-640

6. Yamasaki T, Hemond C, Eisa M, Ganocy S, Fass R (2018) The changing epidemiology of gastroesophageal reflux disease: are patients getting younger. J Neurogastroenterol Motil 24(4): 559-569.

7. Khan M, Santana J, Donnellan C, Preston C, Moayyedi P (2007) Medical treatments in the short term management of reflux oesophagitis. Cochrane Database of Systematic Reviews 2:CD003244.

8. El-Serag H, Becher A, Jones R (2010) Systematic review: persistent reflux symptoms on proton pump inhibitor therapy in primary care and community studies. Aliment Pharmacol Ther 32: 720-737.

9. Hershcovici T, Fass R (2010) An algorithm for diagnosis and treatment of refractory GERD. Best Pract Res Clin Gastroenterol 24: 923-936.

10. Fass R (2019) Approach to refractory gastroesophageal reflux disease in adults. Nicholas J Talley and Shilpa Grover (eds.), USA.

11. Yadlapati R, Vaezi MF, Vela MF, Spechler SJ, Shaheen NJ, et al. (2018) Management options for patients with GERD and persisent symptoms on proton pump inhibitors: recommendations from an expert panel. Am J Gastroenterol 113: 980-986.

12. Frazzoni M, Piccoli M, Conigliaro R, Frazzoni L, Melotti G (2014) Laparoscopic fundoplication for gastroesophageal reflux disease. World J Gastroenterol 20(39): 14272-14279.

13. Gotley DC, Morgan AP, Ball D, Owen RW, Cooper MJ (1991) Composition of gastro-oesophagel refluxate. Gut 32: 1093-1099.

14. Hofmann AF, Mysels KJ (1992) Bile solubility and precipitation in vitro and in vivo: the role of conjugation, $\mathrm{pH}$, and $\mathrm{Ca} 2+$ ions. J Lipid Res 33(5) 617-626.

15. Nehra D, Howell P, Williams CP, Pye JK, Beynon J (1999) Toxic bile acids in gastro-oesophageal reflux disease: influence of gastric acidity. Gut 44 598-602.

16. Tack J, Koek G, Demedts I, Sifrim D, Janssens J (2004) Gastroesophagea reflux disease poorly responsive to single-dose proton pump inhibitors in patients without Barrett's esophagus: acid reflux, bile reflux, or both. Am J Gastroenterol 99(6): 981-988.
17. Nasr AO, Dillon MF, Conlon S, Downey P, Chen G, et al. (2012) Acid suppression increases rates of Barrett's esophagus and esophageal injury in the presence of duodenal reflux. Surgery 151(3): 382-390.

18. Alsalahi O, Dobrian AD (2015) Proton pump inhibitors: the culprit for Barrett's esophagus. Front Oncol 4(article 373): 1-5.

19. Prichard DO, Byrne AM, Murphy JO, Reynolds JV, O'Sullivan J, et al (2017) Deoxycholic acid promotes development of gastroesophageal reflux disease and Barrett's oesophagus by modulating integrin-alphaV trafficking. J Cell Mol Med 21(12): 3612-3625.

20. Sun D, Wang X, Gai Z, Song X1, Jia X, et al. (2015) Bile acids but not acidic acids induce Barrett's esophagus. Int J Clin Exp Pathol 8(2): 1384-1392.

21. Souza RF, Bayeh L, Spechler SJ, Tambar UK, Bruick RK (2017) A new paradigm for GERD pathogenesis. Not acid injury, but cytokine-mediated inflammation driven by HIF-2a: a potential role for targeting HIF-2a to prevent and treat reflux esophagitis. Curr Opin Pharmocol 37: 93-99.

22. Kivilaakso E, Fromm D, Silen W (1980) Effect of bile salts and related compounds on isolated esophageal mucosa. Surgery 87: 280-285.

23. Lillemoe KD, Johnson LF, Harmon JW (1982) Role of the components of gastroduodenal content in experimental acid esophagitis. Surgery 92: 276-284.

24. Chen X, Oshima T, Shan J, Fukui H, Watari J, et al. (2012) Bile salts disrupt human esophageal squamous epithelial barrier function by modulating tight junction proteins. Am J Physiol Gastrointest Liver Physiol 303: G199-G208.

25. Ghatak S, Reveiller M, Toia L, Ivanov AI, Zhou Z, et al. (2016) Bile salts at low $\mathrm{pH}$ cause dilation of intercellular spaces in In Vitro stratified primary esophageal cells, possibly by modulating Wnt Singaling. J Gastrointest Surg 20: 500-509.

26. Huo X, Juergens S, Zhang X, Rezaei D, Yu C, et al. (2011) Deoxycholic acid causes DNA damage while inducing apoptotic resistance through NF-kB activation in benign Barrett's epithelial cells. Am J Physiol Gastrointest Liver Physiol 301(2): G278-G286.

27. Nagashima R (1981) Development and characteristics of sucralfate. J Clin Gastroenterol 3(Suppl2): 103-110.

28. Oshea S (2019) Office of Combination Products. Request for Designation Sucralfate $\mathrm{HCl}$ Topical Paste.

29. Kashimura K, Ozawa K (1999) Sucralfate Preparations, USA.

30. McCullough RW (2019) Relationship between mucosal healing and symptomatic relief in erosive GERD - a four arm randomized trial involving omeprazole, ranitidine, antacids and a barrier therapy -cross-linked polymeric sucralfate (Esolgafate). 6th Annual Congress of the European Society for Translational Medicine (EUSTM-2019) Vienna, Austria. European Journal of Molecular \& Clinical Medicine Vol 6.

31. Patel I, Rarus R, Tan X, Lee EK, Guy J, et al. (2015) Investigation of comparative effectiveness research in Asia, Europe and North America. Indian J Pharma 47(6): 585-593.

32. Medical Research Council of Bangladesh. Clinical Trial Registry 2004 2005.

33. Fraser AG, Butchart EG, Szymański P, Caiani EG, Crosby S, et al. (2018) The need for transparency of clinical evidence for medical devices in Europe. Lancet 392: 521-530.

34. (2015) International Medical Device Regulators Forum. ISO 14155:2011. Clinical investigation of medical devices for human subjects-Good clinical practice.

35. Mathews DR, Dahl NG (1995) Safety of Sucralfate. In: Daniel Hollander GNJ Tytgat(eds.), Plenum Press, Sucralfate: From Basic Science to the Bedside, New York, pp. 215-223.

36. Shiovitz TM, Bain EE, McCann DJ, Skolnick P, Laughren T, et al. (2016) Mitigating the Effects of Nonadherence in Clinical Trials. The Journal of Clinical Pharmacology 56(9): 1151-1164. 
37. Hetzel DJ, Dent J, Reed WD, Narielvala FM, Mackinnon M, et al. (1988) Healing and relapse of severe peptic esophagitis after treatment with omeprazole. Gastroenterology 95: 903-912.

38. Khan M, Santana J, Donnellan C, Preston C, Moayyedi P (2007) Medical treatments in the short term management of reflux oesophagitis. Cochrane Database Syst Rev 2: CD003244.

39. Vermeijden JR, Tytgat GN, Schotborgh RH, Dekker W, vd Boomgaard DM, et al. (1992) Combination therapy of sucralfate and ranitidine, compared with sucralfate monotherapy, in patients with peptic reflux esophagitis. Scand J Gastroenterol 27(2): 81-84.

40. Haastrup PF, Thompson w, Sondergaard J, Jarbel DE (2018) Side effects of long-term proton pump inhibitor use: a review. Basic Clin PHarmacol Toxicol 123(2): 114-121.

41. Vial T, Goubier C, Bergeret A (1991) Side effects of ranitidine. Drug Saf 6(2): 94-117.

42. Maton PN, Burton ME (1999) Antacids revisited: a review of their clinical pharmacology and recommended therapeutic use. Drugs 57(6): 855870.

43. (2013) Risk Profile of Sucralfate. P. 1-27.

44. Giesing D, Lanman R, Runser D (1982) Absorption of sucralfate in man Gastroenterol 82(5pt2): 1066

45. Haram EM, Weberg R, Berstad A, (1987) Urinary excretion of aluminum after ingestion of sucralfate and an aluminum-containing antacid in man. Scand J Gastroenterology 22(5): 615-618.

46. Krewski D, Yokel RA, Nieboer E, Borchelt D, Cohen J, et al. (2007) Human health risk assessment for aluminium, aluminium oxide and aluminium hydroxide. J Toxicol Environ Health B Crit Rev 10(10): 1-269.

47. Priest ND, Talbot RJ, Newton D, Day JP, King SJ, et al. (1998) Uptake by man of aluminium in a public water supply. Hum Exp Toxicol 17: 296 301.

48. Stauber JL, Florence TM, Davies CM et al. (1999) Bioavailability of Al in alum-treated drinking water. J Am Water Works Assoc 91: 84-93.

49. Weberg R, Berstad A (1986) Gastrointestinal absorption of aluminium from single doses of aluminium containing antacids in man. Eur J Clin Invest 16: 428-432.

50. Weberg R, Berstad A, Ladehaug B, Thomassen Y (1986) Are aluminum containing antacids during pregnancy safe? Acta Pharmacol Toxicol (Copenh) 59: 63-65

51. Chao HH, Guo CH, Huang CB, Chen PC, Li HC, et al. (2014) Arsenic, cadmium, lead, and aluminium concentrations in human milk at early stages of lactation. Pediatr Neonatol 55(2): 127-134.

52. Fanni D, Ambu R, Gerosa C, Nemolato S, Iacovidou N et al. (2014) Aluminum exposure and toxicity in neonates: a practical guide to halt aluminum overload in the prenatal and perinatal periods. World J Pediatr 10(2): 101-107.

53. (2014) European Commission Scientific Committee on Consumer Safety. Opinion on the safety of aluminum in cosmetic products. European Union.

54. Katz PO, Gerson LB, Vela MF (2013) Guidelines for the diagnosis and management of gastroesophageal reflux disease. Am J Gastroenterol
108: $308-328$

55. Holtzer P (2011) Transient receptor (TRP) channels as drug targets for diseases of the digestive system. Pharmcol Ther 131(1): 142-170.

56. Holtzer P (2015) Acid-sensing ion channels in gastrointestinal function. Neuropharmacology 94: 72-129.

57. Li WT, Luo QQ Wang B, Chen X, Yan XJ, et al. (2019) Bile acids induce visceral hypersensitivity via mucosal mast cell-to-nociceptor signaling that involves the farnesoid X receptor/nerve growth factor/transient receptor potential vanilloid 1 axis. FASEB J 33(2): 2435-2450.

58. Kim JJ, Kim N, Choi YJ, Kim JS, Jung HC (2016) Increased TRPV1 and PAR2 mRNA expression levels are associated only with the esophageal reflux symptoms but not with extrasophageal reflux symptoms. Mediine (Baltimore) 95(32): e4387.

59. Chen K, Zhang ZF, Liao MF, Yao WL, Wang J, et al. (2015) Blocking PAR2 attenuates oxaliplatin-induced neuropathic pain via TRPV1 and releases of substance P and CGRP in superficial dorsal horn of spinal cord. J Neurol Sci 15: 62-67.

60. Yoshida N, Katada K, Handa O, Takagi T, Kokura S, et al. (2007) Interleukin-8 production via protease-activated receptor 2 in human esophagel epithelial cells. Int J Mol Med 19: 335-340.

61. McCullough RW, McCullough JJ (2017) Deciphering the pathophysiology of irritable bowel syndrome and functional gastrointestinal disorders-an alternative model for pathogenesis:cytokine controlled transepithelial multi-feedback loop. Transl Gastroenterol Hepatol 2:1 8 .

62. Kedika RR, Souza RF, Spechler SJ (2009) Potential Anti-inflammatory Effects of Proton Pump Inhibitors: A Review and Discussion of the Clinical Implications. Dig Dis Sci 54(11): 2312-2317.

63. Handa O, Yoshida N, Fujita N, Tanaka Y, Ueda M, et al. (2006) Molecular mechanisms involved in anti-inflammatory effects of proton pump inhibitors. Inflamm Res 55: 476-482.

64. Chatfield S (1999) A comparison of the efficacy of the alginate preparation, Gaviscon Advance, with placebo in the treatment of gastro-oesophageal reflux disease. Curr Med Res Opin 15(3): 152-159.

65. Savarino V, Pace F, Scarpignato C (2017) Randomised clinical trial: mucosal protection combined with acid supression in the treatment of non-erosive reflux disease - efficacy of Esoxx, a hyaluronic acidchondroitin sulphate based bioadhesive formulation. Aliment Pharmacol Ther 45(5): 631-642.

66. Savarino V, Di Mario F, Scarpignato C (2009) Proton pump inhibitors in GORD: an overview of their pharmacology, efficacy and safety. Pharmacol Res 59: 135-153.

67. Scarpellini E, Ang D, Pauwels A, De Santis A, Vanuytsel T, et al. (2016) Management of refractory typical GERD symptoms. Nat Rev Gastroenterol Hepatol 13(5): 281-294.

68. Roman S, Mion F (2018) Refractory GERD, beyond proton pump inhibitors. Curr Opin Pharmacol 43: 99-103.

69. Coleman HG, Xie SH, Lagergren J (2018) The epidemiology of esophageal adenocarcinoma. Gastroenterol 154: 390-405.

70. Dulai GS, Guha S, Kahn KL, Gornbein J, Weinstein WM (2002) Preoperative prevalence of Barrett's esophagus in esophageal adenocarcinoma: a systematic review. Gastroenterology 122(1): 26-33. 